\title{
Programmable Syringe Pump for Selective Micro Droplet Deposition
}

\author{
Erry Dwi Kurniawan ${ }^{\text {a, }}$, Alwin Adam ${ }^{\text {b }}$, Muhammad Ichlasul Salik ${ }^{\text {, }}$ \\ Paulus Lobo Gareso ${ }^{b}$ \\ ${ }^{a}$ Research Center for Electronics and Telecommunication \\ Indonesian Institute of Sciences \\ Kampus LIPI, Jl. Sangkuriang Building 20, Floor $4^{\text {th }}$ \\ Bandung, Indonesia \\ ${ }^{b}$ Department of Physics \\ Hasanuddin University \\ Kampus UNHAS, Tamalanrea Km. 10 \\ Makassar, Indonesia \\ ${ }^{c}$ Department of Electrical Engineering \\ Sepuluh November Institute of Technology \\ Kampus ITS, Building A, B, C, and AJ, Sukolilo \\ Surabaya, Indonesia
}

\begin{abstract}
Micro/nanopatterns with micro deposition techniques have been used in various applications such as flexible electronic devices, biosensing, and biological tissue engineering. For depositing a small size of droplets that can be controlled, structured and patterned precisely is a very important process for microfabrication. In this study, we developed a low cost and simple system for fabricating micro/nanostructure by a selective micro deposition process using a syringe pump. This method is an additive fabrication method where selective droplet materials are released through a needle of the syringe pump. By translating the rotating stepper motor into a linear movement of the lead screw, it will press the plunger of the syringe and give a force to the fluid inside the syringe, hence a droplet can be injected out. The syringe pump system consists of a syringe, the mechanical unit, and the controller unit. A stepper motor, the lead screw, and the mechanical components are used for the mechanical unit. Arduino Uno microcontroller is used as the controller unit and can be programmed by the computer through GUI (Graphical User Interface). The input parameters, such as the push or pull of flow direction, flow rate, the droplet volume, and syringe size dimension can be inputted by the user as their desired value via keypad or the computer. The measurement results show that the syringe pump has characteristics: the maximum average error value of the measured volume is $2.5 \%$ and the maximum average error value of the measured flow rate is $14 \%$. The benefits of a syringe pump for micro deposition can overcome photolithography weaknesses, which require an etching and stencil process in the manufacture of semiconductors. Combining two or more syringes into one system with different droplet materials can be used as a promising method for 3D microfabrication in the future.
\end{abstract}

Keywords: Droplets, GUI processing, micro deposition, syringe pump.

\section{INTRODUCTION}

Micro/nanopatterns with micro deposition techniques have been used in various applications such as flexible electronic devices, microfluidics [1]-[4], biological tissue engineering [5], surface micromachining [6], pharmaceutical application [7]-[8], dispersive liquid-liquid microextraction [9]-[10], bioprinting sensing [11], etc. For depositing a small size of droplets that can be controlled, structured and patterned precisely is a very important process for micro fabrication.

In the micro metal manufacturing industry [12]-[14], such as micro-circuit printing and metal parts fabrication, 3D metal parts are made with liquid metal droplets in the process.

\footnotetext{
* Corresponding Author.

Email: erry.2k@gmail.com

Received: December 04, 2019 ; Revised: December 10, 2019

Accepted: December 16, 2019 ; Published: December 31, 2019

(C) 2019 PPET - LIPI
}

By an additive manufacturing deposition technique, the liquid metal droplets are produced from metal parts directly without expensive energy sources or special powders [12]. Micro thin-walled metal parts are much difficult to be fabricated because they are very easy to deform under the action of stress, heat, and vibration in the manufacturing process. By analyzing the principle of micro-metal droplets deposition using a syringe pump, a model for quantitative indicators a surface characterizing section is proposed to predict surface evaluation indexes quality developed. With a well-formed formulation, the average height of the arithmetic and section stratification angles can be calculated [13]-[14].

Asphaltene deposition in micro-channels using a syringe pump was also studied [15]. A dual-drive syringe pump that having two glass syringes, a collection tank and a microscope for flow visualization were used in this study. The syringe pump is used to mix two fluids (crude oil and n-heptane) to generate a mixing working fluid flowing at a designed flow rate. 
For the microfluidic device application, micromachining surfaces is a popular tool for cell and tissue engineering because it produces significant the diffusion-based microcavities system. Inkjet printing methods for fabricating these microfluidics devices have been developed. The difficulty in the case of surface micromachining lies in injecting a proper amount of fluid into the microchannel [16]. Small volumes of reagents and samples are needed for use in microfluidic systems, combined with the broad ability to make highperformance microfluidic chips using polydimethylsiloxane (PDMS).

PDMS-based microfluidic devices are used in a variety of applications including immunoassays, proteins, and DNA. The sorting and manipulation of living cells allow the researchers to gain insight into cell biology. The microfluidic system has become one of the more productive tools for the researchers. However, microfluidic systems are not limited to biological research, such as those conducted by nanotechnology researchers as the manufacture of high-yielding nanodevices and as electrophoresis and chromatography conducted by analytical chemistry researchers [1].

Microfluidic is used in the multidisciplinary field which investigates the behavior of metric micro and nanoscale fluids. Applications of microfluidic devices are such as biosensing, immunosensing, microcapsule fabrication, etc. The channels in microfluidic devices can be used to control fluid movement in micro or nanometric volumes to achieve functionality in flowing, mixing, stopping, cleaning, and removing fluid flow. Typically, polydimethylsiloxane (PDMS) is a polymer material used for the manufacture of microfluidic devices. In the laboratory, an infusion pump is used to inject a small volume of liquid into a microfluidic device. Control parameters such as slider speed, resulting in flow rate, fluid viscosity are the main factors in controlling various flow functions [2].

The syringe pump can be used to inject the liquid at a controlled level. It can be used to provide a small amount of liquid in various media such as high viscous liquids, chemicals, adhesives, and other flammable and reactive liquids. Syringe pumps have been previously designed that are used as applications in medicine and pharmacology. Silicone micropumps have a good performance for disposable drug delivery systems, delivering liquid medicines used in the medical field, used as hyper dermis syringes to inject electromagnetic energy into reclining tissue, storing various nanofilms of multiple flow injection analysis - syringes, variable flow rate syringe pumps for the synthesis of nano Fe2P rods, etc. The problem faced with syringe pump design is the observed difference in the measured flow rate compared to the desired flow rate. The actual flow rate lags behind the calculated value due to the designed inaccuracies and the friction pressure drops at various interfaces. The knowledge of errors helps in designing syringe pumps with appropriate flow rates [3].
A fluid flow control system has been developed in a polydimethylsiloxane (PDMS) microfluidic device based on polyimide film lamination [2]. The syringe pump is designed with a flow rate of $100 \mu \mathrm{L}$ and $1000 \mu \mathrm{L} / \mathrm{min}$ which is controlled by a stepper motor through an Arduino microcontroller system.

In this study, we developed a low cost and simple system for fabricating micro/nanostructure by a selective micro deposition process using a syringe pump. This method is an additive fabrication method where selective droplet materials are released through a needle of the syringe pump. The summary of the state of the art and our proposed system can be seen in Table 1 .

The basic theory of the syringe pump is described in Section II. Then, the designed system is explained in Section III. In section III, the results and discussion are reported. Finally, we conclude the research study in the Conclusion.

TABLE 1

COMPARISON OF PREVIOUS STUDY OF SYRINGE PUMP SYSTEM APPLICATION

\begin{tabular}{|c|c|c|c|}
\hline No. & Application & Controller System & Refs \\
\hline \multirow[t]{4}{*}{1.} & \multirow[t]{4}{*}{ Microfluidics } & $\begin{array}{l}\text { ATmega328P } \\
\text { microcontroller }\end{array}$ & {$[1]$} \\
\hline & & Arduino Uno & {$[2]$} \\
\hline & & Arduino Nano & {$[3]$} \\
\hline & & Arduino Mega 2560 & [4] \\
\hline 2. & $\begin{array}{l}\text { 3D biological } \\
\text { tissues }\end{array}$ & 3D printers system & [5] \\
\hline 3 & $\begin{array}{l}\text { Surface } \\
\text { machining }\end{array}$ & 8051 microcontroller & {$[6]$} \\
\hline \multirow[t]{2}{*}{4.} & \multirow[b]{2}{*}{$\begin{array}{l}\text { Pharmaceutical } \\
\text { application } \\
\text { (controlling } \\
\text { dosing of } \\
\text { reagents, } \\
\text { drug delivery) }\end{array}$} & Raspberry Pi & {$[7]$} \\
\hline & & $\begin{array}{l}\text { Computer (Empower } \\
\text { Software) }\end{array}$ & [8] \\
\hline \multirow[t]{2}{*}{5.} & \multirow{2}{*}{$\begin{array}{l}\text { Dispersive } \\
\text { liquid-liquid } \\
\text { microextraction }\end{array}$} & $\begin{array}{l}\text { Computer (AutoAnalysis } 5.0 \\
\text { software) }\end{array}$ & [9] \\
\hline & & Computer (FIALab software) & {$[10]$} \\
\hline 6. & $\begin{array}{l}\text { Bioprinting, } \\
\text { embedded } \\
\text { printing, and } \\
\text { food printing) }\end{array}$ & 3D printers system & {$[11]$} \\
\hline \multirow[t]{2}{*}{7.} & \multirow[t]{2}{*}{$\begin{array}{l}\text { Micrometal } \\
\text { microdeposition }\end{array}$} & $\begin{array}{l}\text { Programmable Multi Axis } \\
\text { Controller (PMAC) }\end{array}$ & $\begin{array}{r}12, \\
13]\end{array}$ \\
\hline & & Industrial personal computer & {$[14]$} \\
\hline 8. & $\begin{array}{l}\text { Asphaltene } \\
\text { deposition }\end{array}$ & 3D microscopy system & {$[15]$} \\
\hline 9. & $\begin{array}{l}\text { Diffusion-based } \\
\text { concentration } \\
\text { control in } \\
\text { microcavities }\end{array}$ & $\begin{array}{l}\text { Computer controlled } \\
\text { syringe pump (TS-1B, } \\
\text { Longer-Pump Company) }\end{array}$ & {$[16]$} \\
\hline 10. & $\begin{array}{l}\text { Micro droplet } \\
\text { deposition for } \\
\text { 3D sensor } \\
\text { fabrication }\end{array}$ & $\begin{array}{l}\text { Arduino Uno (Processing } \\
\text { software through computer } \\
\text { and keypad for standalone) }\end{array}$ & $\begin{array}{l}\text { This } \\
\text { work }\end{array}$ \\
\hline
\end{tabular}




\section{Syringe PUMP}

A syringe is made up of three parts: the plunger, the barrel, and the tip. The tip of the syringe is where a needle is sometimes attached by a hub. Figure 1 shows the illustration of the parts of the syringe. By applying the pressure to the plunger, the fluid inside the barrel can be injected out of the syringe depending on its pressure.

According to Pascal's principle, an external input pressure applied to a fluid in a closed vessel is uniformly transmitted without loss to every portion of the fluid. Because liquids are incompressible, the inlet flow rate $\left(Q_{1}\right)$ into an area must equal to the outlet flow rate $\left(Q_{2}\right)$ out of an area as the Equation of Continuity, following the Equation (1).

$$
\begin{gathered}
Q_{1}=Q_{2} \\
A_{1} v_{1}=A_{2} v_{2}
\end{gathered}
$$

where $Q$ is the flow rate, $v$ is the velocity of the fluid, and $A$ is the area of the cross-section of the space the fluid is moving through.

The pressure to be applied for the desired flow rate can be determined by Bernoulli's Equation following

$$
\frac{P_{1}}{\rho g}+\frac{v_{1}^{2}}{2 g}+z_{1}=\frac{P_{2}}{\rho g}+\frac{v_{2}^{2}}{2 g}+z_{2}
$$

Bernoulli's Equation is a statement of energy conservation. The equation states that the sum of the pressure head, the velocity head, and the elevation head is constant along a streamline. The pressure head $(P / \rho g)$ represents the height of a column of the fluid that is needed to produce pressure $(P), \rho$ is the density of the fluid at all points in the fluid, and $g$ is the acceleration due to gravity. The velocity head $\left(v^{2} / 2 g\right)$ represents the vertical distance needed for the fluid to fall freely (neglecting friction) if it is to reach velocity $(v)$ from the rest. The elevation head $(z)$ is related to the potential energy of the particle.

In our designed system, the inlet and the outlet of the syringe are the same horizontal position. So, the elevation head of the inlet and outlet are the same $\left(z_{l}=z_{2}\right)$. On the other hand, the applied force to the plunger can be determined by the following Equation (4).

$$
F_{1}=P_{1} \times A_{1}
$$

Assuming the outlet pressure is in atmosphere condition, the inlet is slightly higher than the outlet at a low flow rate. Therefore, Equation (3) can be expressed as the following:

$$
\frac{P_{1}}{\rho g}=\frac{v_{1}^{2}}{2 g}-\frac{v_{2}^{2}}{2 g}+11.21
$$

By substituting Equation (4) to Equation (5), the force required to push the fluid out of the syringe can be formulated by the following:

$$
F_{1}=\left(\frac{v_{1}^{2}-v_{2}^{2}}{\rho}\right) A_{1}+11.21 g
$$

The force requirement would determine the torque of the stepper motor for the designed system.

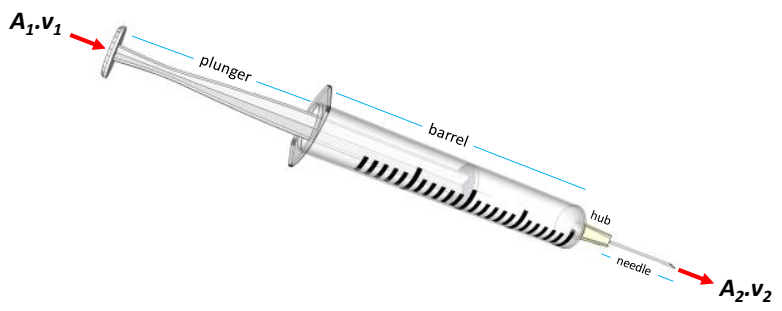

Figure 1. Parts of the syringe

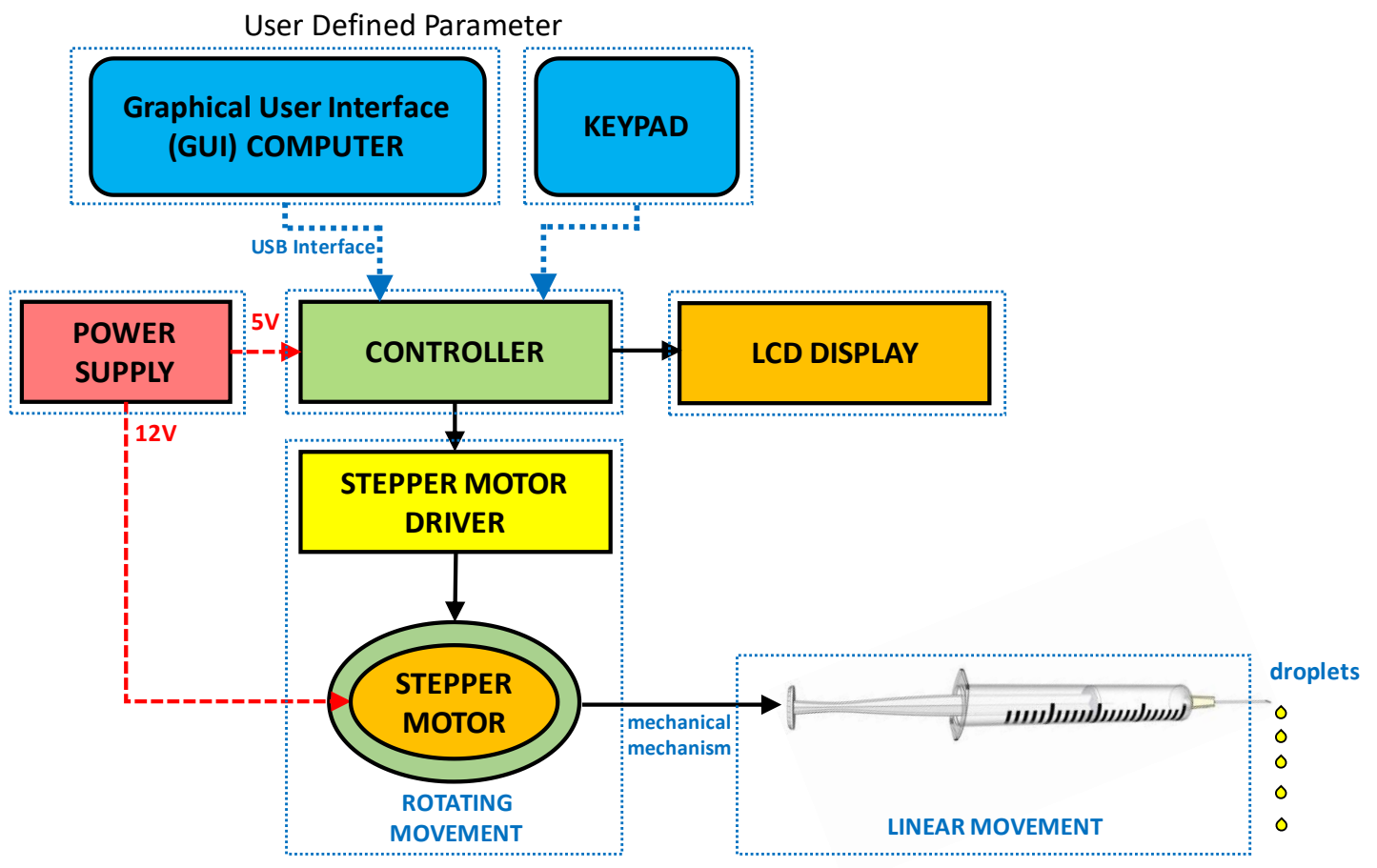

Figure 2. The block diagram of the programmable syringe pump system 


\section{SYSTEM DESIGN}

Figure 2 shows the block diagram of the programmable syringe pump system for selective microdroplet deposition. The syringe pump system consists of a syringe, the mechanical unit, and the controller unit. A stepper motor, the lead screw, and the mechanical components are used for the mechanical unit. By translating the rotating stepper motor into a linear movement of the lead screw, it will press the plunger of the syringe and give a force to the fluid inside the syringe, hence a droplet can be injected out.

The stepper motor used in this study is a 4-wire bipolar motor with minimum torque $4 \mathrm{~kg}$ - $\mathrm{cm}$ according to Equation (5). This bipolar stepper has a $1.8^{\circ}$ step angle (200 steps per revolution) under operating voltage $12 \mathrm{~V}$ power supply. For driving this stepper motor, DRV8825 as a micro-stepping motor driver is chosen. It features over-current and over-temperature protection, adjustable current limiting, and six micro-step resolutions (down to $1 / 32$-step). It operates from $8.2 \mathrm{~V}$ to $45 \mathrm{~V}$ and can deliver up to approximately $1.5 \mathrm{~A}$ per phase without a heat sink or forced air flow (rated for up to $2.2 \mathrm{~A}$ per coil with sufficient additional cooling). The rotating speed and direction of the motor stepper will be controlled by the controller unit. The electronics circuit schematic of the programmable syringe pump system can be seen in Figure 3.

Arduino Uno microcontroller is used as the controller unit and can be programmed by the computer through the Graphical User Interface (GUI). The input parameters, such as the push or pull of flow direction, flow rate, the droplet volume, and syringe size dimension can be inputted by the user as their desired value via keypad or the computer. The Liquid Crystal Display (LCD) is used to display the input parameters and its settings. The power supply of the system is separated into $5 \mathrm{~V}$ for the controller unit and $12 \mathrm{~V}$ for the stepper motor.

The Graphical User Interface (GUI) of the programmable syringe pump system can be seen in Figure 4. The GUI is developed using Processing open software. The users can choose the moving direction of the syringe by selecting a PUSH or PULL button, then the stepper motor will rotate clockwise $(\mathrm{CW})$ or counterclockwise $(\mathrm{CCW})$ to meet this setting.

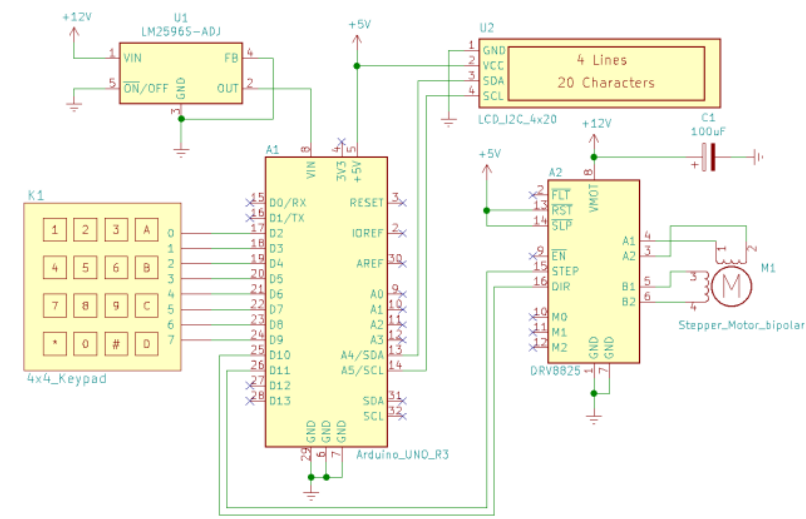

Figure 3. The electronics circuit schematic of the programmable syringe pump system
Afterward, the flow rate and volume of fluid that want to be injected can be inputted. The program storing in the controller will calculate how much time that the motor needed to rotate. Another important setting is the syringe diameter. The user can input the diameter depending on the syringe size used in the system. After all the settings are correct, the WRITE button must be clicked to store the settings. Next, the START button can be clicked to start the operation.

The Graphical User Interface (GUI) of the programmable syringe pump system can be seen in Figure 4. The GUI is developed using Processing open software. The users can choose the moving direction of the syringe by selecting a PUSH or PULL button, then the stepper motor will rotate clockwise $(\mathrm{CW})$ or counterclockwise $(\mathrm{CCW})$ to meet this setting. Afterward, the flow rate and volume of fluid that want to be injected can be inputted. The program storing in the controller will calculate how much time that the motor needed to rotate. Another important setting is the syringe diameter. The user can input the diameter depending on the syringe size used in the system. After all the settings are correct, the WRITE button must be clicked to store the settings. Next, the START button can be clicked to start the operation.

The programmable syringe pump system is constructed from 3D printed parts combined with a standard mechanical component as shown in Figure 5. The acrylonitrile butadiene styrene (ABS) plastic is used as the parts materials and designed using a CAD software program. The $3 \mathrm{D}$ design files then are exported to STL files and to be printed by a 3D printing platform. Subsequently, the parts are assembled with standard mechanical parts, such as a lead screw, couplings, bearing, linear shaft and connected to a stepper motor. The pitch of the lead screw will have determined the minimum resolution of displacement. In our designed system, a $2 \mathrm{~mm}$ pitch with 4 start lead screw combining with $1 / 32$ micro-stepping motor driver can achieve 1.25 $\mu \mathrm{m}$ per step. The realization of the prototype of the programmable syringe pump system can be seen in Figure 6. A simple and portable prototype is successfully developed.

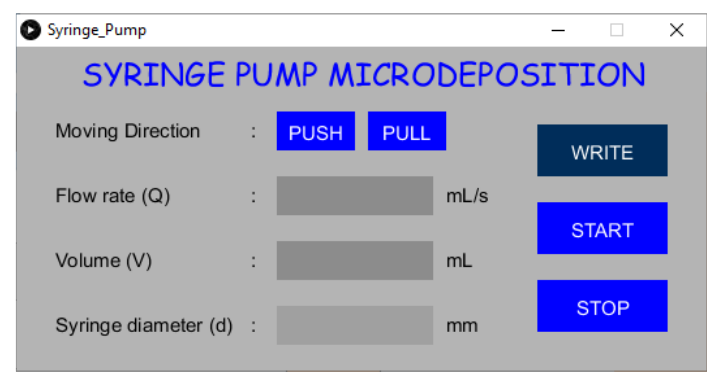

Figure 4. The prototype of the programmable syringe pump system

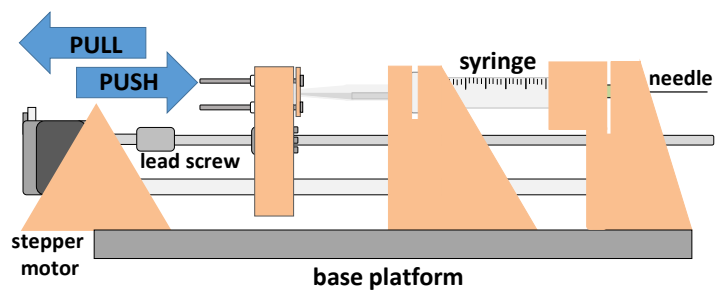

Figure 5. 3D design of the programmable syringe pump system 


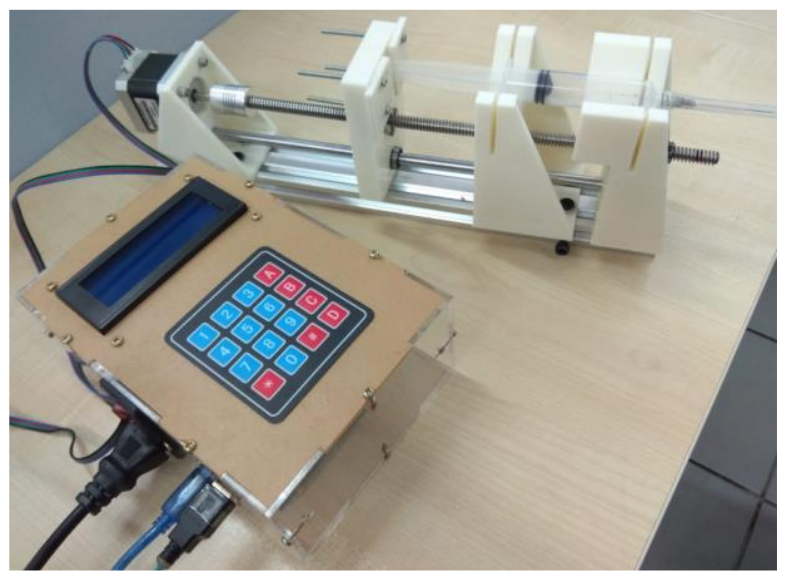

Figure 6 . The prototype of the programmable syringe pump system

\section{RESUlt AND Discussion}

In this paper, to find out the accuracy of the syringe pump with a small volume, the four-volume size of syringes are used. A $12 \mathrm{~mL}, 6 \mathrm{~mL}, 3 \mathrm{~mL}$, and $1 \mathrm{~mL}$ syringe with the diameter of each syringe of $16 \mathrm{~mm}, 13$ $\mathrm{mm}, 10 \mathrm{~mm}$, and $5 \mathrm{~mm}$, respectively are investigated. Before measuring the volume and flow rate of the injected fluid out from the syringe, the accuracy of the displacement of linear movement is measured.

To calculate the shift distance movement of the displacement, it can be formulated using Equation (7). According to the specification of the motor stepper and lead screw used in the design, the number of steps per revolution is divided by lead screw pitch can calculate the relationship of desired movement and step of the stepper motor.

$$
\begin{aligned}
\frac{\# \text { of steps per rev }}{\text { lead screw pitch }} & =\frac{200\left[\frac{\text { steps }}{\mathrm{rev}}\right]}{2\left[\frac{\mathrm{mm}}{\mathrm{rev}}\right]} \\
& =100 \mathrm{steps} / \mathrm{mm}
\end{aligned}
$$

The steps of the stepper motor are varied from 500 to 4000 steps using 4 different syringe pumps that have different volumes to shift the displacement from $5 \mathrm{~mm}$ to $40 \mathrm{~mm}$. Table 2 shows the measurement results of the step of the stepper motor to the linear movement of the syringe.

The control algorithm based on Equation in Section 2 is translated into a programmed code in Arduino. The definition of speed, delay, and motor step are calculated by the following:

$$
\begin{aligned}
& \text { motor speed }=\frac{\text { flow rate }(Q)}{2 \times 0.25 \times \text { diameter } x \text { diameter }} \\
& \text { time delay }=\frac{150}{\text { motor speed }} \\
& \text { motor step }=\frac{\text { volume } x 4}{\pi x \text { diameter } x \text { diameter }} \times \frac{200}{2}
\end{aligned}
$$

Using Equation (8), the system will automatically perform as the desired value as user that inputted through GUI or keypad.

TABLE 2

\begin{tabular}{|c|c|c|c|c|c|c|c|c|c|c|c|c|}
\hline \multirow{2}{*}{$\begin{array}{c}\text { Desired } \\
\text { Volume } \\
(\mathrm{mL})\end{array}$} & \multicolumn{3}{|c|}{$12 \mathrm{~mL}$ syringe } & \multicolumn{3}{|c|}{$6 \mathrm{~mL}$ syringe } & \multicolumn{3}{|c|}{$3 \mathrm{~mL}$ syringe } & \multicolumn{3}{|c|}{$1 \mathrm{~mL}$ syringe } \\
\hline & $\begin{array}{c}\begin{array}{c}\text { Measured } \\
\text { Volume } \\
(\mathrm{mL})\end{array} \\
\end{array}$ & $\begin{array}{c}\text { Time } \\
(\mathrm{s})\end{array}$ & $\begin{array}{l}\text { Flow rate } \\
(\mathrm{mL} / \mathrm{min})\end{array}$ & $\begin{array}{c}\text { Measured } \\
\text { Volume } \\
(\mathrm{mL})\end{array}$ & $\begin{array}{c}\text { Time } \\
(\mathrm{s})\end{array}$ & $\begin{array}{l}\text { Flow rate } \\
(\mathrm{mL} / \mathrm{min})\end{array}$ & $\begin{array}{c}\text { Measured } \\
\text { Volume } \\
(\mathrm{mL}) \\
\end{array}$ & $\begin{array}{l}\text { Time } \\
(\mathrm{s})\end{array}$ & $\begin{array}{l}\text { Flow rate } \\
(\mathrm{mL} / \mathrm{min})\end{array}$ & $\begin{array}{c}\text { Measured } \\
\text { Volume } \\
(\mathrm{mL}) \\
\end{array}$ & $\begin{array}{c}\text { Time } \\
(\mathrm{s})\end{array}$ & $\begin{array}{l}\text { Flow rate } \\
(\mathrm{mL} / \mathrm{min})\end{array}$ \\
\hline 0.5 & - & - & - & - & - & - & - & - & - & 0.5 & 26.04 & 1.152074 \\
\hline 1 & 1 & 7.04 & 8.522 & 1 & 9.29 & 6.458 & 1 & 17.87 & 3.357 & 1 & 53.07 & 1.130582 \\
\hline 2 & 2 & 14.18 & 8.462 & 2 & $\begin{array}{l}18.4 \\
\end{array}$ & 6.521 & 2 & 36.68 & 3.271 & - & - & - \\
\hline 3 & 3 & 22.56 & 7.978 & 3 & 27.48 & 6.550 & 2.9 & 53.63 & 3.244 & - & - & - \\
\hline 4 & 3.8 & 28.13 & 8.105 & 3.9 & 36.47 & 6.416 & - & - & - & - & - & - \\
\hline 5 & 4.9 & 35.44 & 8.295 & 5 & 45.56 & 6.584 & - & - & - & - & - & - \\
\hline 6 & 5.7 & 42.15 & 8.113 & 6 & 54.95 & 6.551 & - & - & - & - & - & - \\
\hline 7 & 6.7 & 49.2 & 8.170 & - & - & - & - & - & - & - & - & - \\
\hline 8 & 7.7 & 55.96 & 8.255 & - & - & - & - & - & - & - & - & - \\
\hline
\end{tabular}

MEASUREMENT DATA OF STEP OF STEPPER MOTOR TO THE LINEAR MOVEMENT OF SYRINGE

\begin{tabular}{|c|c|c|c|c|c|}
\hline \multirow{2}{*}{$\begin{array}{c}\text { Step of } \\
\text { Stepper Motor }\end{array}$} & \multirow{2}{*}{$\begin{array}{c}\text { Desired } \\
\text { Movement }(\mathbf{m m})\end{array}$} & \multicolumn{4}{|c|}{ Measured Movement of Syringe (mm) } \\
\cline { 3 - 6 } & $\mathbf{1 2} \mathbf{~ m L}$ & $\mathbf{6} \mathbf{~ m L}$ & $\mathbf{3} \mathbf{~ m L}$ & $\mathbf{1} \mathbf{~ m L}$ \\
\hline 500 & 5 & 5 & 4.5 & 5 & 5 \\
\hline 1000 & 10 & 10 & 10 & 10 & 10 \\
\hline 1500 & 15 & 15 & 14.5 & 14.5 & 15 \\
\hline 2000 & 20 & 19 & 19 & 19.5 & 19.5 \\
\hline 2500 & 25 & 25 & 24.5 & 24.5 & 24.5 \\
\hline 3000 & 30 & 30 & 29.5 & 29 & 29.5 \\
\hline 3500 & 35 & 35 & 34.5 & 34 & 34.5 \\
\hline 4000 & 40 & 39 & 39 & 39 & 39 \\
\hline
\end{tabular}

TABLE 3

MEASUREMENT DATA OF INJECTED VOLUME AND FLOWRATE OF THE SyRINGE 
The data from Table 2 then are plotted into a relationship graph that can be shown in Figure 7 with the desired movement as the $\mathrm{x}$-axis and measured movement as the $y$-axis. The results show the measured movement does not have a significantly different from the desired movement calculated using a formula in Equation (7). The graph shows a linear relationship between both desired and measured movement parameters. The inset inside Figure 7 shows the deviation error of movement. We can see the maximum percentage of the average error is $3.23 \%$ at a $6 \mathrm{~mL}$ syringe with a maximum span of 10 $\%$. Moreover, the best average error can be achieved by $0.94 \%$ at $12 \mathrm{~mL}$ syringe. However, the error span is $5 \%$. Overall, the average displacement error of this system is still below 5\%. It means the system has a high-accuracy of displacement of linear movement. To achieve very accurate displacement, the closed-loop system can be considering adding the proximity sensor as the input.

Next, we fill the syringe with the water for testing the syringe pump performances. The water will be injected out from the syringe by varying volume from the user. We also diverge the syringe size by changing the diameter size through the GUI computer. Table 3 collects the measurement data of injected volume and flow rate of the syringe. The desired volumes are inputted from 0.5 $\mathrm{mL}$ to $8 \mathrm{~mL}$. Then, the injected fluid out of the syringe is measured. Meanwhile, the period when the system starts until stop also is measured by a stopwatch. Figure 8 depicts the measurement results of this experiment.

In measuring the volume of the syringe pump with a different volume of $12 \mathrm{~mL}, 6 \mathrm{~mL}, 3 \mathrm{~mL}$, and $1 \mathrm{~mL}$, the measured volume is not much different from the desired volume. The volume differences are between $0.1-0.4$ $\mathrm{mL}$. Then, the flow rate $(\mathrm{mL} / \mathrm{min})$ can be calculated by the volume divided by time. The average flow rates are $8.2,6.5,3.3,1.1 \mathrm{~mL} / \mathrm{min}$ for $12,6,3,1 \mathrm{~mL}$ syringe respectively. The calculation results show the differences between the desired flow rate with the measured flow rate of $0.1-0.5 \mathrm{~mL} / \mathrm{min}$.

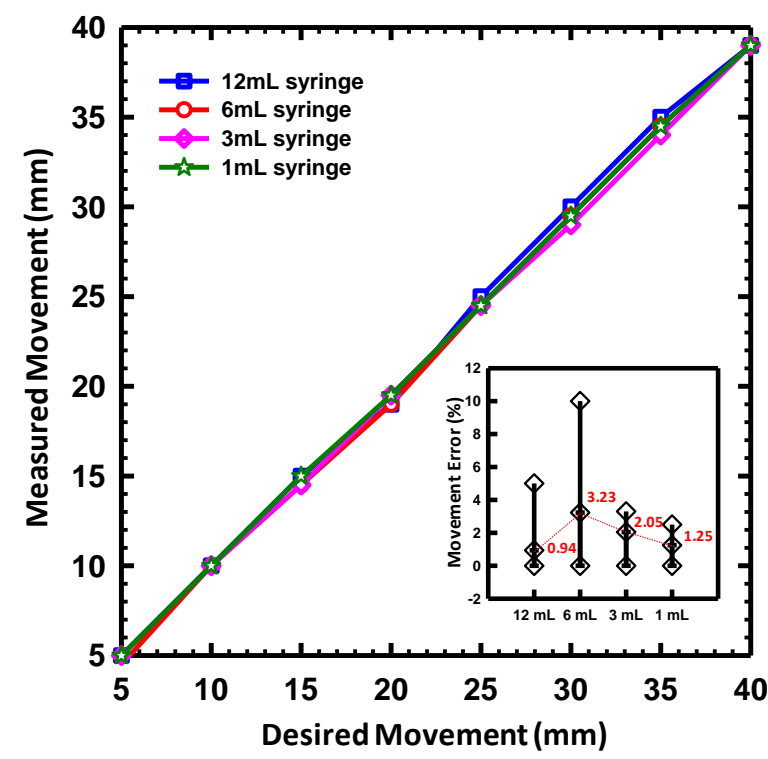

Figure 7. The measurement results of linear movement of lead screw with inset their movement deviation error

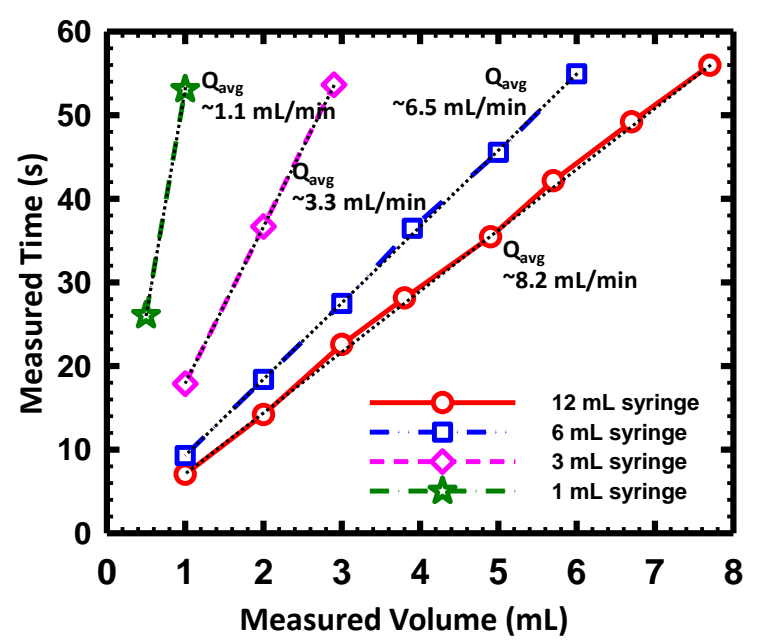

Figure 8. The measurement results of volume and time of injected fluid out from syringe.

The volume and flow rate error bar is plotted in Figure 9 (a) and (b). The maximum error span of four types of the syringe is $5 \%$ with the maximum average error is $2.5 \%$ at $12 \mathrm{~mL}$ syringe. While the maximum average error flow rate is $14 \%$ at $1 \mathrm{~mL}$ with a very narrow error span. With a smaller diameter of the syringe, the expected accuracy of the flow rate becomes smaller. For making very precision flow rates and injected volumes, the pressure sensor can be attached to this system.
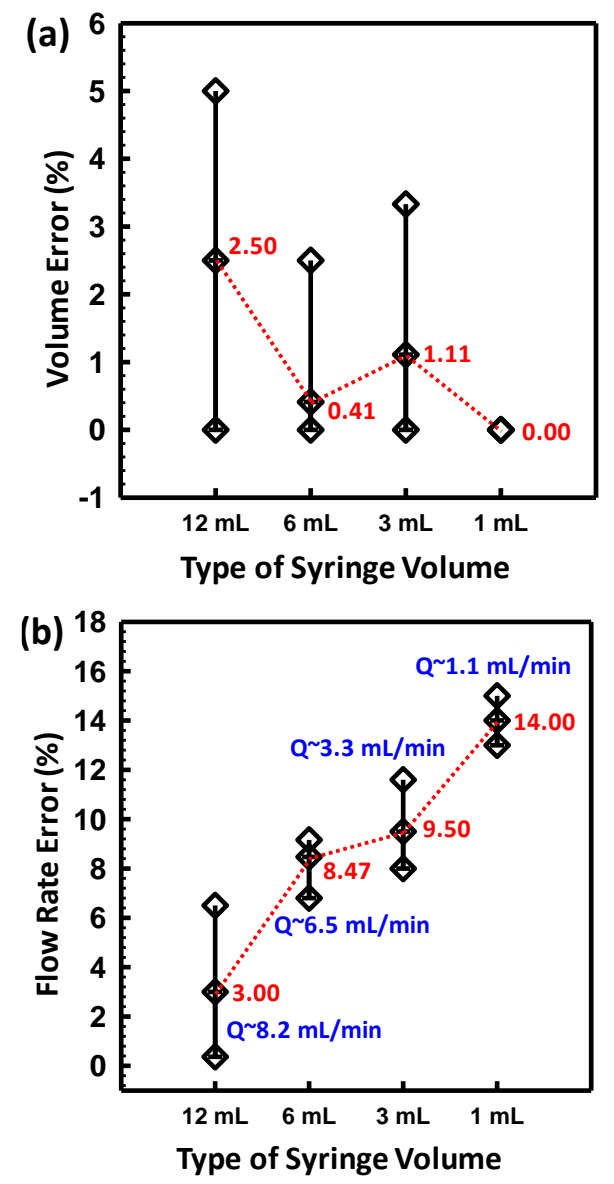

Figure 9. (a) The error bar of measured volume and (b) the error bar of measured flow rate of the syringe pump system with different type of syringe volume. 
For testing this system on the microdroplet deposition process, we have deposited positive photoresist S1805 on the alumina substrate with dimension $20 \mathrm{~mm} \times 20 \mathrm{~mm}$ for the photolithography process. A micro-liter photoresist from 1 to $10 \mu \mathrm{L}$ is injected carefully by controlling the displacement of the syringe. The experiment results can be seen in Figure 10 (a). A droplet of photoresist will spread circularly to the surface of the substrate. The area surface of the deposition subsequently is measured using ImageJ open software analysis. Figure 10 (b) shows the relationship between injected volume to the surface of the microdroplet deposition. The nearly linear relationship can be seen in these results. The coefficient of determination $\left(\mathrm{R}^{2}\right)$ value is 0.944 . In other words, $\mathrm{r}$ squared tells the experimental data nearly fit the regression model. It can be explained that this system can deposit the photoresist with good precision.

For the application of $3 \mathrm{D}$ microfabrication, this microdroplet deposition system can be assembled with a $3 \mathrm{D}$ printing platform. Assuming we use conductive material pasta, we can make a geometry pattern on the substrate to fabricate the sensor, flexible electronics device, etc. With a different material, we also can make a different layer of material to make a vertical device structure.

(a)
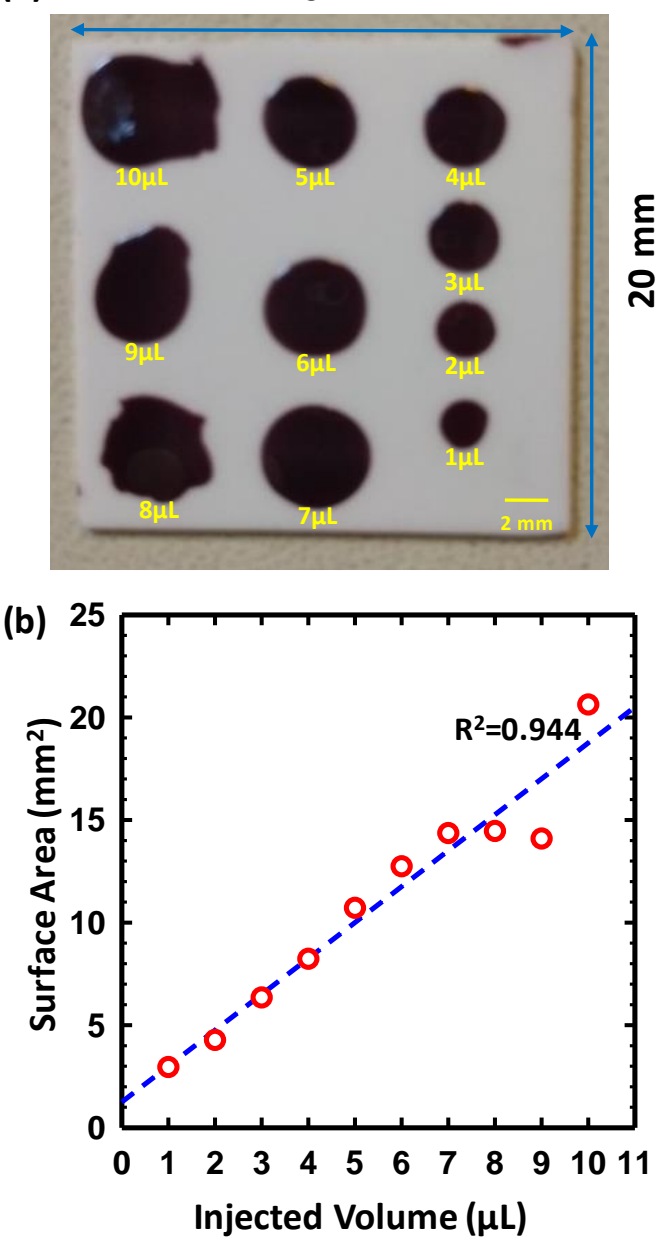

Figure 10. (a) Microdroplet deposition of positive photoresist S1805 on the alumina substrate (b) The relationship plot between injected volume to surface area of the deposition

\section{CONCLUSION}

In this paper, we reported that the designed system has some good performances. It shows a linear relationship between both desired and measured movement parameters. Besides, the measured volume at the different syringe pump volumes does not significantly different from the desired volume. The volume differences are between $0.1-0.4 \mathrm{~mL}$ which the maximum average error value of the measured volume is $2.5 \%$. The calculation results show the differences between the desired flow rate with the measured flow rate of $0.1-0.5 \mathrm{~mL} / \mathrm{min}$ with the maximum average error value of the measured flow rate is $14 \%$. Overall, the system can be used as a promising method for 3D microfabrication by microdroplet deposition techniques for fabricating $3 \mathrm{D}$ sensor or electronics devices in the future. By adding the proximity sensor or pressure sensor to control the movement and injected volume as a closedloop system, this system can achieve superior accuracy. Moreover, by combining two or more syringes into one system with different droplet materials, the perfect system for 3D microfabrication can be realized.

\section{ACKNOWLEGDEMENT}

The authors would like to thank Research Center for Electronics and Telecommunications, Indonesian Institute of Sciences that supported this research.

\section{REFERENCES}

[1] J. R. Lake, K. C. Heyde, and W. C. Ruder, "Low-cost feedbackcontrolled syringe pressure pumps for microfluidics applications," Journal PloS ONE, vol. 12, no. 4, e0175089, 2017.

[2] K. S. Tee, M. S. Saripan, H. Y. Yap, and C. F. Soon, "Development of a mechatronic syringe pump to control fluid flow in a microfluidic device based on polyimide film," in IOP Conf. Series: Materials Science and Engineering 226, 012031, 2017.

[3] A. Polák, "Design and Fabrication of Controllable Syringe Pumps for Microfluidics," Thesis, Faculty of Electrical Engineering, Czech Technical University, Prague, Czech, 2017.

[4] J. M. Neumaier, A. Madani, T. Klein, and T. Ziegler, "Lowbudget 3D-printed equipment for continuous flow reactions," Beilstein Journal of Organic Chemistry, vol. 15, 558-566, 2019.

[5] L. Serex, A. Bertsch, and P. Renaud, "Microfluidics: A New Layer of Control for Extrusion-Based 3D Printing," Micromachines, 9(2), 86, 2018, doi: 10.3390/mi9020086.

[6] M. S. V. Appaji, S. Reddy G., Arunkumar S., and Venkatesan M., "An 8051 microcontroller based syringe pump control system for surface micromachining," in Proc. Materials Science 5, 2014, pp. 1791-1800.

[7] B. Wijnen, E. J. Hunt, G. C. Anzalone, and J. M. Pearce, "Opensource syringe pump library," Journal PloS ONE, vol. 9, no. 9, e107216, 2014

[8] C. Bazin, A-L. Poirier, and D. Dupoiron, "Influence of $\mathrm{pH}$ and temperature on ziconotide stability in intrathecal analgesic admixtures in implantable pumps and syringes," International Journal of Pharmaceutics, vol. 487, 285-291, 2015.

[9] R. M. Frizzarin, F. M. José, and M. E. V. Cerdà, "Fullyautomated in-syringe dispersive liquid-liquid microextraction for the determination of caffeine in coffee beverages," Food Chemistry, vol. 212, 759-767, 2016.

[10] K. Fikarova, B. Horstkotte, H. Sklenarova, F. Svec, and P. Solich, "Automated continuous-flow in-syringe dispersive liquid-liquid microextraction of mono-nitrophenols from large sample volumes using a novel approach to multivariate spectral analysis," Talanta, vol. 202, 11-20, 2019.

[11] K. Pusch, T. J. Hinton, and Adam W. Feinberg, "Large volume syringe pump extruder for desktop 3D printers," HardwareX, vol. 3, 49-61, 2018. 
[12] D. Zhang, L. Qi, J. Luo, H. Yi, X. Hou, and H. Li, “Geometry control of closed contour forming in uniform micro metal droplet deposition manufacturing," Journal of Materials Processing Technology 243, 474-480, 2017.

[13] Y-P. Chao, L-H. Qi, Y. Xiao, J. Luo, and J-M. Zhou, "Manufacturing of micro thin-walled metal parts by microdroplet deposition," Journal of Materials Processing Technology, vol. 212, 484-491, 2012.

[14] L-H. Qi, S-Y. Zhong, J. Luo, D-C. Zhang, and H-S Zuo "Quantitative characterization and influence of parameters on surface topography in metal micro-droplet deposition manufacture," International Journal of Machine Tools \& Manufacture, vol. 88, 206-213, 2015.

[15] Y. Zhuang, A. Goharzadeh, Y. J. Lin, Y. F.Yap, J. C. Chai, N. Mathew, F. Vargas, and S. L. Biswal, "Three dimensional measurements of asphaltene deposition in a transparent microchannel," Journal of Petroleum Science and Engineering, vol. $145,77-82,2016$

[16] G. Si, X. Zhu, Y. Kang, C. Luo, Q. Ouyang, and Y. Chen, "Diffusion-based concentration control in microcavities during long time period by programmed syringe pumps," Microelectronic Engineering 87, 793-797, 2010. 